\title{
Analisis Pengaruh Kedisiplinan Kerja, Prestasi Kerja Dan Semangat Kerja Terhadap Pemberian Bonus Karyawan Pada PT. Reka Sukses Adipratama
}

\author{
Andy \\ Manajemen, Universitas Buddhi Dharma, Banten, Indonesia \\ Sutrisna \\ Manajemen, Universitas Buddhi Dharma, Banten, Indonesia
}

\begin{abstract}
ABSTRAK
Penelitian ini dilakukan dengan tujuan untuk mengetahui seberapa besar pengaruh tingkat kedisiplinan, prestasi kerja dan semangat kerja terhadap pemberian bonus karyawan pada PT. Reka Sukses Adipratama. Penelitian ini menggunakan metode koefisien korelasi berganda, analisis regresi berganda serta koefisien determinasi untuk uji hipotesis.

Berdasarkan hasil penelitian diperoleh bahwa persamaan regresi linear berganda $Y=$ $28,274+0,373 \mathrm{X}_{1}-0,283 \mathrm{X}_{2}+0,285 \mathrm{X}_{3}$, artinya hubungan antara kedisiplinan kerja, prestasi kerja dan semangat kerja adalah sangat kuat dan mempunyai bentuk hubungan yang positif, dibuktikan dengan koefisien korelasi variabel kedisiplinan kerja $\left(X_{1}\right)$ sebesar 0,373 mendekati 1 , besar hubungan prestasi kerja $\left(X_{2}\right)$ ditunjukan dengan nilai koefisien korelasi sebesar 0,283 mendekati 1 dan besar hubungan semangat kerja $\left(X_{3}\right)$ ditunjukan dengan nilai koefisien korelasi sebesar 0,285 mendekati 1. Hal ini berarti dapat dikatakan bahwa kedisiplinan kerja, prestasi kerja dan semangat kerja yang berlaku pada PT. Reka Sukses Adipratama berjalan baik untuk meningkatkan pemberian bonus.

Dari hasil koefisien penentu dalam model summary, menunjukan koefisien korelasi yaitu sebesar 0,154 yang menunjukan adanya hubungan antara kedisiplinan kerja, prestasi kerja dan semangat kerja yang sangat kuat. Besarnya pengaruh kedisiplinan kerja, prestasi kerja dan semangat kerja diperoleh sebesar $15 \%$, sedangkan sisanya 85\% dipengaruhi oleh faktor-faktor lain.

Dari hasil analisis uji hipotesis diperoleh bahwa $\mathrm{t}$ hitung untuk kedisiplinan kerja adalah sebesar 3,541, $\mathrm{t}$ hitung untuk prestasi kerja adalah sebesar 2,207 dan $\mathrm{t}$ hitung untuk semangat kerja adalah sebesar 2,114. Dengan $\quad t$ hitung kedisiplinan kerja lebih besar dari $t$ tabel 3,541>1, $t$ hitung prestasi kerja lebih besar dari $t$ tabel atau 2,207 $>1,960$ dan $t$ hitung semangat kerja lebih besar dari t tabel atau 2,114>1,960 maka kondisi tersebut menunjukan bahwa Ho ditolak dan Ha diterima.

Dari uji hipotesis didapat $\mathrm{f}$ hitung adalah 6,293 dengan tingkat signifikan 0,000. Angka $0.000<0.05$, dengan demikian Ho ditolak dan Ha menerima, artinya terdapat hubungan linear antara variabel kedisiplinan kerja, prestasi kerja dan semangat kerja dengan pemberian bonus karyawan.
\end{abstract}

Kata kunci: Kedisiplinan kerja, Prestasi kerja, Semangat kerja, Pemberian, bonus karyawan. 


\title{
Understanding the Relationship between Affective Commitment and Continuity Commins at Buddhi College Tangerang
}

\begin{abstract}
This study was conducted with the aim to find out how much influence the level of discipline, work performance and morale towards giving employees bonuses at PT. Reka Sukses Adipratama. This research uses multiple correlation coefficient method, multiple regression analysis and coefficient of determination for hypothesis test.

Based on the result of research, it can be concluded that multiple linear regression equation $Y$ $=28,274+0,373 X 1-0,283 X 2+0,285 X 3$, it means that the correlation between work discipline, job performance and morale is very strong and have positive relation, proved by correlation coefficient of work discipline variable (X1) equal to 0.373 close to 1 , the magnitude of work performance correlation (X2) is shown with correlation coefficient value of 0.283 close to 1 and the relationship of morale (X3) is shown with the value of correlation coefficient of 0.285 approaching 1. This means that it can be said that work discipline, work performance and morale applicable at PT. Reka Sukses Adipratama runs well to increase bonuses.

From the results of the determinant coefficient in the summary model, showed the correlation coefficient of 0.154 which shows the relationship between work discipline, job performance and a very strong morale. The amount of influence of work discipline, job performance and morale is obtained by $15 \%$, while the remaining $85 \%$ is influenced by other factors.

From result of hypothesis test analysis obtained that $t$ count for work discipline is equal to 3,541 , t count for work achievement is equal to 2,207 and t count for work spirit is equal to 2,114 . With $t$ count the discipline of work greater than $t$ table $3.541>1, t$ calculate the performance of work greater than t table or 2.207> 1.960 and $t$ arithmetic working spirit greater than t table or 2.114> 1.960 then the condition shows that Ho is rejected and $\mathrm{Ha}$ be accepted.

From the hypothesis test obtained f count is 6.293 with a significant level of $0.000 .0 .000<0.05$, thus Ho is rejected and Ha receives, it means there is a linear relationship between the variables of work discipline, work performance and morale with the giving of employee bonus.
\end{abstract}

Keyword: Discipline work, Job achievement, Morale, Employee bonus granting. 


\section{PENDAHULUAN}

Setiap organisasi tentunya mempunyai berbagai tujuan yang hendak dicapainya. Tujuan tersebut diraih dengan mendayagunakan sumber daya yang ada. Kendatipun berbagai sumber daya yang ada yang penting bagi organisasi, salah satunya adalah faktor sumber daya manusia dan bagaimana sumber daya itu dikelolah (Hasibuan, Malayu, 2007).

Asset organisasi paling penting yang harus dimiliki oleh perusahaan dan sangat diperhatikan oleh manajemen adalah asset manusia dari organisasi tersebut. Sumber daya manusia merujuk kepada orangorang dalam organisasi. Tidak ada satupun faktor dalam aktivitas bisnis yang mempunyai dampak langsung terhadap kesejahteraan perusahaan selain daripada sumber daya manusia.

Adapun yang membuat suatu organisasi dapat mencapai tujuannya adalah dengan manajemen sumber daya manusia yang efektif. Yang dimaksud dengan manajemen sumber daya yang efektif itu sendiri adalah pendayagunaan sumber daya manusia yang tepat menyangkut pemahaman terhadap kebutuhan individual maupun organisasional agar potensi sumber daya manusia dapat digarap secara penuh. Salah satu hal yang dapat diterapkan dalam menggali potensi sumber daya manusia antara lain dengan penerapan kedisiplinan yang baik, pemberian insentif atau bonus yang sesuai dengan prestasi kerja. Disiplin kerja sering kali menimbulkan kesan yang negatif bagi para karyawan, karena lebih dikaitkan dengan sanksi atau hukuman. Kedisiplinan kerja adalah sikap dan tingkah laku yang menunjukan ketaatan karyawan terhadap peraturan organisasi (James A.F. Stoner, 2006).

Sikap dan perilaku dalam kedisiplinan kerja ditandai oleh berbagai inisiatif, kemauan dan kehendak untuk menaati peraturan. Artinya, orang yang dikatakan mempunyai disiplin yang tinggi sematamata patuh dan taat terhadap peraturan secara kaku dan mati, tetapi juga mempunyai kehendak untuk menyesuaikan diri dengan peraturanperaturan organisasi.

Kenyataan yang tidak dapat dipungkiri, sebelum masuk dalam sebuah organisasi, seorang karyawan tentu mempunyai aturan, nilai dan norma sendiri, yang merupakan proses sosialisasi dari keluarga atau masyarakatnya. Seringkali terjadi aturan, nilai dan norma diri tidak sesuai dengan aturan-aturan organisasi yang ada. Hal ini menimbulkan konflik sehingga 
orang mudah tegang, marah atau Banyak perusahaan yang meyakini bahwa tersinggung apabila orang terlalu sistem imbalan pada umumnya dan menjunjung tinggi salah satu aturannya. insentif pada khususnya mempengaruhi Berdasarkan dari uraian diatas maka dapat prestasi kerja. Selain itu tidak sedikit ditarik kesimpulan bahwa kedisiplinan karyawan yang lebih menyukai bayaran kerja merupakan suatu sikap dan perilaku mereka terkait dengan prestasi kerja yang berniat untuk menaati segala memperkuat motivasi perusahaan untuk peraturan organisasi yang didasarkan oleh menerapkan sistem imbalan ini. Program kesadaran diri untuk menyesuaikan insentif ini berupaya untuk dengan peraturan organisasi (Henry menghubungkan bayaran dengan kinerja simamora, 2006). guna mengimbali prestasi kerja diatas rataDengan adanya kedisiplinan kerja yang rata secara cepat dan langsung. Semangat baik maka dapat berpengaruh pada kerja atau gairah melakukan pekerjaan prestasi kerja karyawan itu sendiri. Prestasi kerja atau kinerja berasal dari kata job performance (prestasi kerja atau prestasi sesungguhnya yang pernah dicapai seseorang). Prestasi kerja adalah hasil kerja yang dicapai seseorang baik berupa produk atau jasa dan dalam pelaksanaan tugas atau pekerjaannya sesuai dengan beban tugas yang harus dilaksanakan dengan disertai adanya standar kerja yang telah ditentukan (Malayu Hasibuan, 2007). Prestasi kerja yang baik merupakan langkah awal untuk menuju tercapainya suatu organisasi. Untuk mendapatkan prestasi kerja yang baik maka perusahaan perlu memberikan insentif berupa suatu pemberian bonus karyawan untuk dapat merangsang prestasi kerja yang baik. yang membuat karyawan yang bermasalah 
tersebut selalu terikat pada sistem kedisiplinan. Perusahaan

mulai menerapkan disiplin kerja guna mengatasi atau mencegah terulangnya kesalahan yang sama pada karyawan itu sendiri ataupun karyawan lainnya.

Penerapan disiplin yang dilakukan oleh perusahaan bagi semua karyawan di perusahaan itu tanpa terkecuali. Para manajer dan supervisor merupakan pihak yang berperan dalam membuat keputusan disiplin dan menjalankan disiplin tersebut. Manajer menerapkan kebijakan pemberian bonus bagi karyawan yang disiplin, berprestasi dan memiliki semangat kerja dalam melaksanakan pekerjaan seharihari. Disiplin yang dimaksud berdasarkan absensi karyawan yang apabila dalam sebulan absennya tidak ada yang terlambat, mentaati peraturan, mengerjakan tugas yang diberikan atasan dan lain-lain maka akan diberikan bonus/insentif. Untuk karyawan yang berprestasi seperti menyelesaikan tugastugas secara efektif, mempunyai ide-ide yang bagus untuk kemajuan perusahaan, dapat menemukan suatu metode kerja baru yang lebih efisien dalam memecahkan masalah, hasil kerja yang melebihi target yang diberikan perusahaan dan lain-lain dan karyawan yang mempunyai semangat kerja dengan suasana kerja yang baik, menghargai antar sesama karyawan, banyaknya karyawan yang produkstif, tingkat upah yang baik. Bila semua ini dijalankan oleh karyawan maka perusahaan akan memberikan bonus yang akan diterima karyawan berdasarkan penilaian yang dilakukan oleh atasannya. Dengan demikian perusahaan mengharapkan karyawan mereka dapat bekerja secara optimal sehingga tingkat kesalahan yang dilakukan oleh karyawan mereka dapat di kurangi, mereka akan lebih giat dalam mengerjakan tugas dan tanggung jawab mereka, dengan penerapan disiplin dan prestasi kerja inilah diharapkan karyawan dapat menyumbangkan tenaga dan pikiran mereka secara optimal bagi perusahaan sehingga pemberian bonus dapat terwujud dengan baik dengan demikian maka tujuan yang telah ditetapkandapat terwujud sesuai dengan apa yang diharapkan oleh perusahaan.

Tujuan penelitian ini sebagai berikut: (1) Untuk mengetahui seberapa besar pengaruh kedisiplinan kerja karyawan di PT. Reka Sukses Adipratama. (2) Untuk mengetahui seberapa besar pengaruh prestasi kerja karyawan di PT. Reka Sukses Adipratama. (3) Untuk mengetahui 
seberapa besar pengaruh semangat kerja di PT. Reka Sukses Adipratama. (4) Untuk mengetahui seberapa besar pengaruh pengaruh kedisiplinan kerja, prestasi kerja dan semangat kerja terhadap pemberian bonus karyawan di PT. Reka Sukses Adipratama

\section{KAJIAN TEORI}

\section{Kedisiplinan Kerja}

Menurut H. Malayu S.P. Hasibuan (2007:193) menyatakan bahwa

Kedisiplinan kerja adalah kesadaran dan kesediaan seseorang menanti semua peraturan perusahaan dan norma-norma sosial yang berlaku.

Menurut Henry simamora (2006:610) menyatakan bahwa :

Kedisiplinan kerja merupakan bentuk pengendalian diri karyawan dan pelaksanaan yang teratur dan menunjukan tingkat kesungguhan tim kerja di dalam sebuah organisasi.

Menurut Anwar Prabu Mangkunegara $(2005: 129)$

$$
\text { menyatakan }
$$

bahwa

Kedisiplinan Kerja merupakan

pelaksanaan manajemen untuk memperteguh pedoman - pedoman organisasi. Menurut James A.F. Stoner (2006:610) yang di terjemahkan oleh Wilhelmus W. Bakowatun dalam bukunya
Manajemen, menyatakan bahwa kedisiplinan umumnya dijalankan bila seseorang karyawan melanggar kebijakan perusahaan atau bekerja tidak sesuai dengan harapan dan manajemen harus turun tangan untuk memperbaiki situasi".

\section{Prestasi Kerja}

Menurut H. Malayu Hasibuan (2007:94) menyatakan bahwa prestasi kerja adalah suatu hasil kerja yang dicapai seseorang dalam melaksanakan tugas-tugas yang dibebankan kepadanya yang didasarkan atas kecakapan, pengalaman, dan kesungguhan serta waktu.

Menurut H. Sadili Samsudin (2006:160) dalam menyatakan bahwa penilaian prestasi kerja karyawan adalah penilaian yang sistematik terhadap penampilan kerja mereka sendiri dan potensi karyawan dalam upaya mengembangkan diri untuk kepentingan organisasi atau perusahaan". Menurut Harold J. Leavitt (2007:192) ada 3 faktor penting yang mempengaruhi prestasi kerja:

1. Manajer menilai prestasi kerja karyawan dengan maksud agar mengetahui mana karyawan-karyawan yang lebih baik

2. Manajer menilai prestasi kerja karyawan dengan maksud agar mereka 
dapat memberikan hadiah atas prestasi kerja yang lebih baik.

3. Manajer menilai prestasi kerja karyawan untuk mendorong karyawan agar bekerja lebih baik.

Menurut T. Hani Handoko (2008:135ł. Menurut Alex S. Nitisenito (2004:96) dalam menyatakan bahwa penilaian pretasi kerja adalah proses melalui mana organisasiorganisasi mengevaluasi atau menilai prestasi kerja karyawan".

Menurut Anwar Prabu Mangkunegara (2005:67) menyatakan bahwa prestasi kerjæ. adalah hasil kerja secara kualitas dan kuantitas yang dicapai oleh seseorang pegawai dalam melaksanakan tugasnya sesuai dengan tanggung jawab yang diberikan kepadanya".

\section{Semangat Kerja}

Menurut Mutiara S. Pangabean (2004:21) dalam bukunya Manajemen Sumber Daya Manusia, ada 2 cara untuk mendefinisikan semangat kerja, sebagai berikut:

a. Semangat kerja adalah kondisi dari sebuah kelompok dimana ada tujuan yang jelas dan tetap dirasakan menjadi penting dan terpadu dengan tujuan individu.

b. Semangat kerja adalah kepemilikian atau kebersamaan. Semangat kerja merujuk kepada adanya kebersamaan, hal ini merupakan rasa pemahaman dengan perhatian terhadap unsurunsur dari pekerjaan seseorang, kondisi kerja, rekan kerja, pimpinan dan perusahaan.

bukunya Manajemen Personalia, menyatakan semangat kerja adalah melakukan pekerjaan secara lebnih giat sehingga pekerjaan diharapkan lebih cepat dan lebih baik.

Menurut Hasibuan dalam bukunya Manajemen Sumber Daya Manusia (2007:94) semangat kerja adalah keinginan dan kesungguhan seseorang mengerjakan pekerjaannya dengan baik serta berdisiplin untuk mencapai prestasi kerja yang maksimal.

\section{Pemberian Bonus}

Menurut Sondang P. siagian (2006:269) dalam bukunya Sumber Daya Manusia menyatakan bahwa pemberian Bonus merupakan insentif dalam bentuk bonus yang diberikan kepada karyawan yang mampu bekerja sedemikian rupa sehingga tingkat produksi yang baku terlampaui. Melampaui tingkat produksi itu terdapat dalam salah satu dari 2 bentuk : 
1. Melampaui tingkat produksi yang dihasilkan dalam kurun waktu tertentu.

2. Apabila terjadi penghematan waktu Artinya jika karyawan menyelesaikan tugas dengan hasil yang memuaskan dalam waktu lebih singkat dari waktu yang seharusnya, karyawan yang bersangkutan menerima bonus dengan alasan bahwa dengan menghemat waktu itu, lebih banyak pekerjaan yang dapat diselesaikan.

Menurut Achmad S. Ruky (2006:185) dalam bukunya Manajemen Penggajian dan Pengupahan untuk Karyawan Perusahaan menyatakan bahwa pemberian Bonus merupakan pemberian pendapatan tambahan bagi karyawan atau pekerja yang hanya diberikan setahun sekali apabila syarat -syarat tertentu dipenuhi.

Menurut Robert L. Mathis dan John H. Jacson (2006:426) dalam bukunya yang berjudul Manajemen Sumber Daya Manusia menyatakan bahwa bonus adalah bayaran satu kali yang tidak menjadi bagian dari gaji pokok karyawan.

\section{METODOLOGI PENELITIAN}

\section{Teknik Analisis Data}

Model persamaan yang akan dibentuk merupakan persamaan regresi berganda, yaitu:

$\mathrm{Y}=\mathrm{b}_{0}+\mathrm{b} 1 \mathrm{X} 1+\mathrm{b} 2 \mathrm{X} 2+\mathrm{b} 3 \mathrm{X} 3+\varepsilon$

Keterangan :

$\mathrm{Y} \quad=$ Pemberian Bonus

$\mathrm{b}_{0} \quad=$ Konstanta

$\mathrm{X} 1=$ Kedisiplinan Kerja

X2 = Prestasi Kerja

$\mathrm{X}_{3}=$ Semangat kerja

B1 ,B2 = Koefisien Regresi

\section{HASIL DAN PEMBAHASAN}

Dalam penelitian ini, penulis mengambil beberapa orang untuk dijadikan sample untuk menjawab pertanyaan-pertanyaan yang penulis ajukan mengenai Analisa Pengaruh Kedisiplinan Kerja, Prestasi Kerja dan Semangat Kerja terhadap Pemberian Bonus Karyawan pada PT. Reka Sukses Adipratama dalam bentuk indikator kepada 108 responden.

Dalam hal ini penulis menganalisa Pengaruh Kedisiplinan Kerja, Prestasi Kerja dan Semangat Kerja terhadap Pemberian Bonus Karyawan pada PT. Reka Sukses Adipratama dengan menggunakan penelitian yang dilakukan dengan membagikan kuesioner. Penulis 
$\begin{array}{ll}\text { memberikan masing-masing } 10 & 10 \\ \text { pertanyaan mengenai kedisiplinan } & \text { kerja }\end{array}$ kepada 108 orang karyawan yang digunakan sebagai sampel. Perincian pembagian sampel dapat dilihat pada di bawah ini.

\section{Uji Normalitas}

Dalam penelitian ini pengujian normalitas data menggunakan uji KolmogorovSmirnov (kolmogororov-smirnov test) dengan pendekatan grafik normal provability plot. Deteksi normalitas degan melihat penyebaran data (titik) pada sumbu diagonal dari grafik. Hasil uji normalitas data yang diperoleh adalah sbb

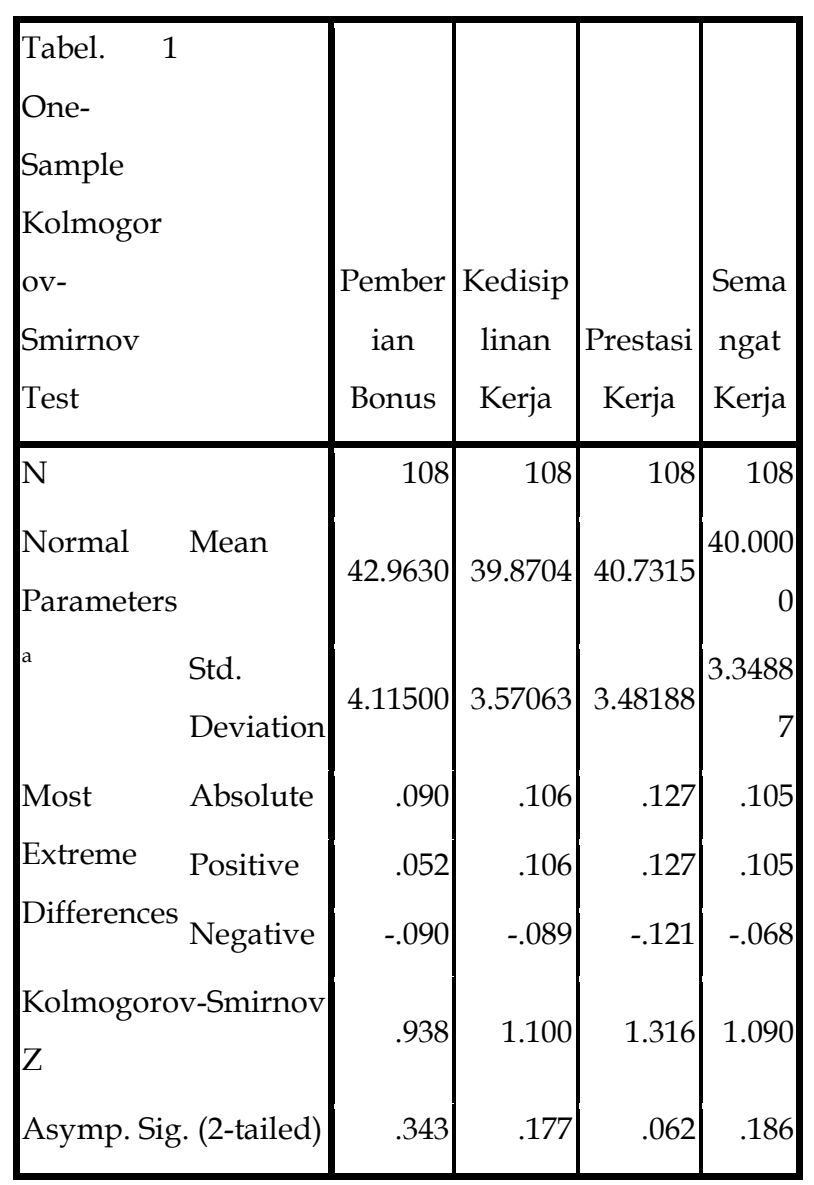

Sumber : Output Spss. V. 16.0

Dari tabel 1 diatas diperoleh nilai signifikan (Sig) untuk Pemberian bonus $(0,343)$ kedisiplinan kerja $(0,177)$ prestasi kerja $(0,062)$ semangat kerja $(0,186)$, sehingga $\mathrm{H}_{0}$ diterima. Dengan demikian dapat disimpulkan bahwa data kedisiplinan kerja, prestasi kerja dan semangat kerja terhadap pemberian bonus berdistribusi normal. Adapun gambar grafik normalitas dapat dilihat seperti nampak berikut ini :

\section{Uji Multikolinieritas}

Pengujian ini dimaksudkan untuk melihat apakah dua atau lebih variabel bebas yang 
berkorelasi secara linier. Apabila terjadi keadaan ini, maka peneliti akan mengalami kesulitan untuk membedakan pengaruh masing-masing variabel bebas terhadap variabel terikat. Untuk mendeteksi adanya gejala multikolinieritas dalam model penelitian dapat dilihat dari nilai toleransi (tolerance value) atau nilai Varian Inflation Factor (VIF). Batas tolerance $>0,10$ dan batas VIF $<10,00$, sehingga dapat disimpulkan tidak terdapat multikilinieritas diantara variabel bebas. Besaran korelasi antar variabel independen dari suatu model regresi yang bebas multikilinieritas, jika koefisien korelasi antar variabel indepenen harus lemah, yaitu dibawah 0,5. Jika korelasi antar variable independen kuat, maka terjadi problem multikilinieritas.

Berdasarkan hasil pengujian terhadap variabel penelitian dapat dilihat seperti nampak pada tabel berikut ini :
Coefficientsa

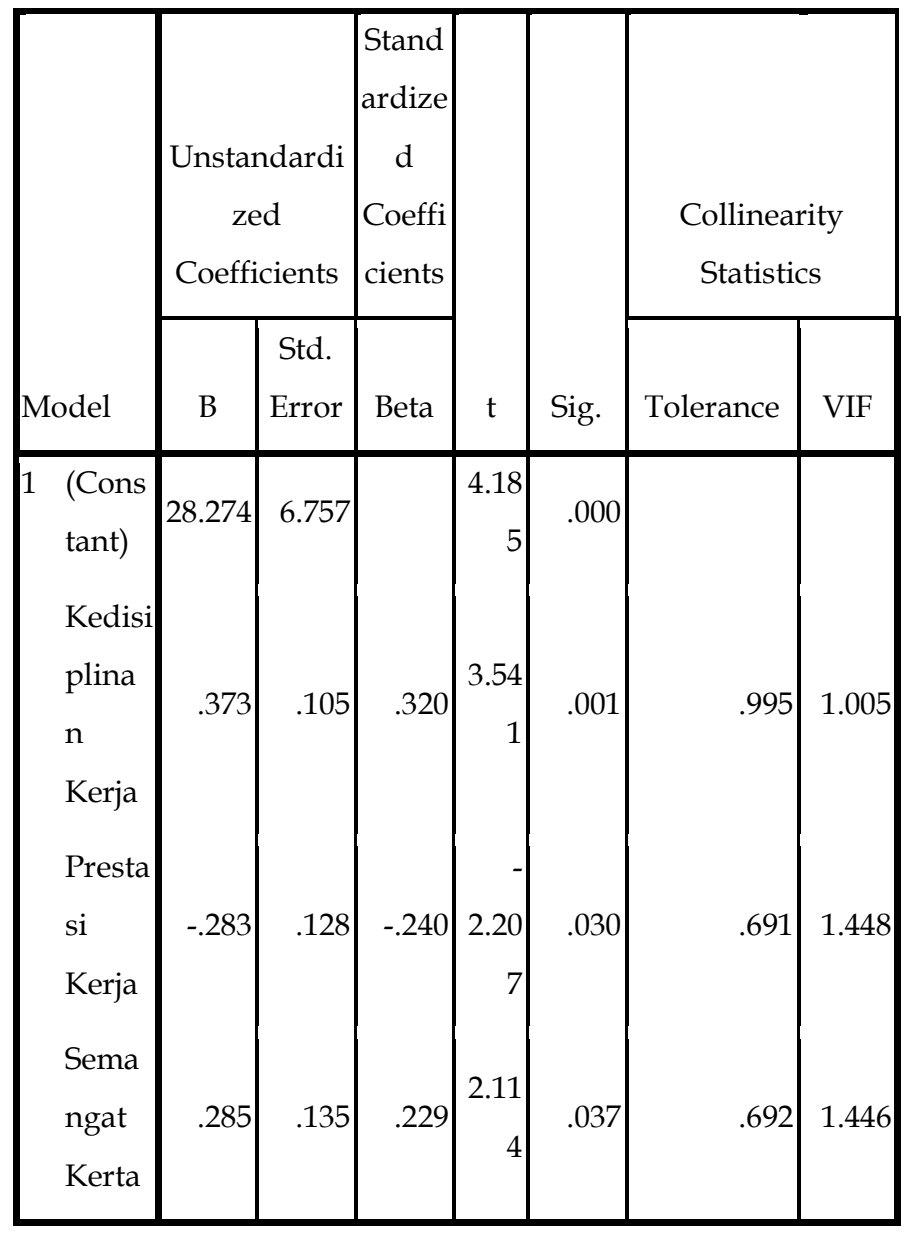

Sumber: Out put SPSS, V.16

Dari hasil perhitungan pada tabel diatas diketahui nilai VIF untuk variabel Disiplin Kerja $\left(\mathrm{X}_{1}\right)$, Prestasi Kerja $\left(\mathrm{X}_{2}\right)$, dan Semangat Kerja $\left(\mathrm{X}_{3}\right)$ memiliki nilai berkisar antara 1,005 sampai dengan 1,448 yang berarti nilai ini dibawah 10 . Selain itu nilai tolerance lebih dari 0,10. Berdasarkan hasil perhitungan uji multikiliniertas tersebut dapat disimpulkan bahwa variabel yang akan diteliti tidak terjadi gejala multikiliniertas.

Hasil pengjujian terhadap gejala multikiliniertas tersebut didukung koefisien 
korelasi antar variabel independent lemah, yaitu dibawah 0,05 sehingga ketiga variabel independen tersebut tidak memiliki persoalan multikolinieritas antara masing-masing variabelnya.

Analisis :

1. Untuk menyusun persamaan regresi dari data diatas, dapat menggunakan nilai-nilai dari kolom B yaitu kolom Unstandardized Coeffiscients. Dari kolom B ini didapat nilai constan (pemberian Bonus) sebesar 28,247 sedangkan untuk nilai koefisien variabel kedisiplinan kerja sebesar 0,373 variabel prestasi kerja sebesar 0,283 dan semangat kerja sebesar 0,285.

2. Nilai koefisien $X_{1}$ (Kedisiplinan Kerja) atau koefisien regresi sebesar 0,373 menyatakan bahwa setiap peningkatan atau penurunan kedisiplinan kerja sebesar 1 point, maka pemberian bonus karyawan akan mengalami peningkatan atau penurunan sebesar 0,373 Sedangkan koefisien $\mathrm{X}_{2}$ (Prestasi Kerja) atau koefisien regresi sebesar 0,283 menyatakan bahwa setiap peningkatan atau penurunan prestasi kerja sebesar 1 point, maka pemberian bonus karyawan akan mengalami peningkatan atau penurunan sebesar 0,283 dan koefisien $\mathrm{X}_{3}$ (Semangat Kerja) atau koefisien regresi sebesar 0,285 menyatakan bahwa setiap peningkatan atau penurunan prestasi kerja sebesar 1 point, maka pemberian bonus karyawan akan mengalami peningkatan atau penurunan sebesar 0,285 .

3. Dari nilai-nilai koefisien diatas, persamaan regresi:

$\mathrm{Y}=28,274+0,373 \mathrm{X}_{1}-0,283 \mathrm{X}_{2}+0,285 \mathrm{X}_{3}$

$\mathrm{Y}=$ Pemberian Bonus Karyawan

$\mathrm{X}_{1}=$ Kedisiplinan Kerja

$\mathrm{X}_{2}=$ Prestasi Kerja

$\mathrm{X}_{3}=$ Semangat Kerja

4. Pada kolom $t$ digunakan untuk pengujian $\mathrm{t}$ untuk menguji kebenaran dari hipotesis yang ada dilakukan dengan cara membandingkan $t$ hitung yang telah diperoleh dengan $t$ table.

Kritera Pengujian :

a. Jika t hitung $>$ tabel maka Ho ditolak dan Ha diterima.

b. Jika t hitung < tabel maka Ho diterima dan Ha ditolak.

Pada kolam $t$ diketahui bahwa $t$ hitung adalah 3,541 (variabel $\left.\mathrm{X}_{1}\right), \quad-2,207$ (variabel X2) dan 2,114 (variable $X_{3}$ ) dengan menggunakan tabel distribusi normal $\mathrm{t}$ dan menggunakan tingkat keyakinan pengujian (1-alpha) sebesar 95\% dan tingkat kesalahan (alpha) 
sebesar 5\%, serta derajat kebebasan Degree of Freedom (D1) n-2 = 106, maka diperoleh nilai distribusi tabel $\mathrm{t}$ adalah $=1,980$ oleh karena $\mathrm{t}$ hitung lebih besar dari $\mathrm{t}$ tabel maka kondisi tersebut menunjukan bahwa Ho ditolak pada tingkat kesalahan 5\% dan Ha diterima pada tingkat keyakinan $95 \%$.

5. Pada kolom sig. digunakan untuk pengujian probabilitas.

Kriteria Pengujian :

a. Jika probabilitas < 0,05 maka Ho ditolak dan Ha diterima.

b. Jika probabilitas > 0,05 maka Ho diterima dan Ha ditolak.

Terlihat bahwa pada kolom sig. Diketahui bahwa nilai probabilitas dari kedisiplinan kerja $(0,001)$, prestasi kerja $(0,030)$ dan semangat kerja $(0,037)$ atau probabilitasnya dibawah 0,05 dengan demikian Ho ditolak atau koefisien regresi signifikan atau kedisiplinan kerja, prestasi kerja dan semangat kerja berpengaruh terhadap pemberian bonus karyawan.
Correlations

\begin{tabular}{|c|c|c|c|c|c|}
\hline & & $\begin{array}{c}\text { Bonu } \\
\mathrm{s}\end{array}$ & $\begin{array}{c}\text { Disipli } \\
\text { n Kerja }\end{array}$ & $\begin{array}{l}\text { Prestas } \\
\text { i Kerja }\end{array}$ & $\begin{array}{c}\text { Semanga } \\
\text { t Kerja }\end{array}$ \\
\hline $\begin{array}{l}\text { Pearson } \\
\text { Correlatio } \\
n\end{array}$ & $\begin{array}{l}\text { Bonus } \\
\text { Disiplin } \\
\text { Kerja } \\
\text { Prestasi } \\
\text { Kerja } \\
\text { Semanga } \\
\text { t Kerja }\end{array}$ & $\begin{array}{r}1.000 \\
.323 \\
-.133 \\
.079\end{array}$ & $\begin{array}{c}.323 \\
1.000 \\
-.065 \\
-.053\end{array}$ & $\begin{array}{l}-.133 \\
-.065 \\
1.000 \\
.555\end{array}$ & $\begin{array}{c}.079 \\
-.053 \\
.555 \\
1.000\end{array}$ \\
\hline $\begin{array}{lr}\text { Sig. } & \text { (1- } \\
\text { tailed) } & \mathrm{I} \\
& \mathrm{I} \\
& \mathrm{I} \\
& \mathrm{t} \\
& \mathrm{t} \\
& \mathrm{I}\end{array}$ & $\begin{array}{l}\text { Bonus } \\
\text { Disiplin } \\
\text { Kerja } \\
\text { Prestasi } \\
\text { Kerja } \\
\text { Semanga } \\
\text { t Kerja }\end{array}$ & .000 & .252 & $\begin{array}{l}.085 \\
.252\end{array}$ & $\begin{array}{l}.207 \\
.292\end{array}$ \\
\hline $\begin{array}{l}\mathrm{E} \\
\mathrm{I} \\
\mathrm{I} \\
\mathrm{I} \\
\mathrm{F} \\
\mathrm{s} \\
\mathrm{t}\end{array}$ & $\begin{array}{l}\text { Bonus } \\
\text { Disiplin } \\
\text { Kerja } \\
\text { Prestasi } \\
\text { Kerja } \\
\text { Semanga } \\
\text { t Kerja }\end{array}$ & $\begin{array}{l}108 \\
108\end{array}$ & $\begin{array}{l}108 \\
108\end{array}$ & $\begin{array}{c}108 \\
108\end{array}$ & $\begin{array}{l}108 \\
108 \\
108 \\
108\end{array}$ \\
\hline
\end{tabular}

Sumber: Out put SPSS, V.16

Dari tabel diatas menunjukkan Pearson Correlation bahwa nilai Disiplin kerja $=$ $(0,323)$, Prestasi Kerja $=(0,133)$, Semangat Kerja $=(0,079)$ dan Bonus $=(1.000)$ dan didapat nilai sig. 0,05, maka dipotesis yang menyatakan bahwa data berasal dari populasi memiliki distribusi normal, sehingga dapat diterima. Dengan 
demikian uji statistik parametrik menggunakan analisis regresi yang akan dilakukan dalam penelitian ini dapat dilakukan.

\section{Uji R dan $\mathbf{R}^{2}$}

Model Summaryb

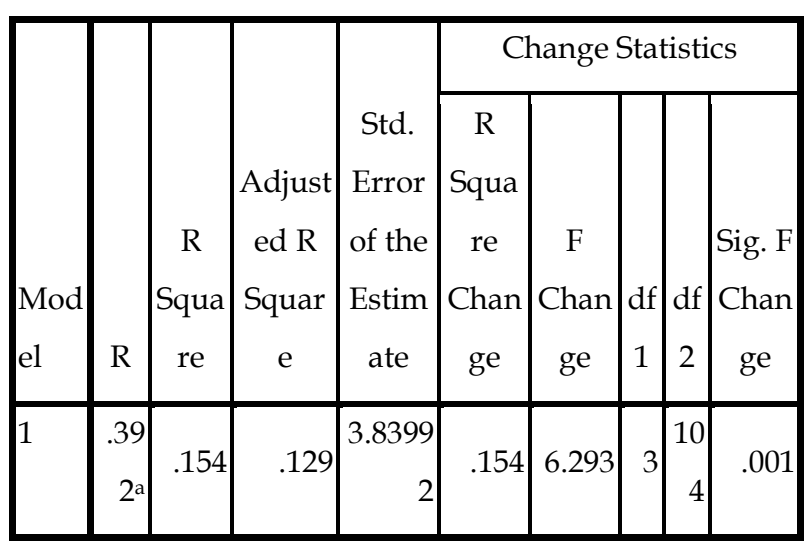

a. Predictors: (Constant), Semangat

Kerja, Disiplin Kerja, Prestasi Kerja

b. Dependent Variable:

Bonus

Sumber: out put SPSS, V.16

Analisis:

1. Kolom $\mathrm{R}$ menunjukan angka koefisien korelasi yaitu sebesar 0,392. Hal ini berarti hubungan antara kedisiplinan kerja, prestasi kerja dan semangat kerja adalah sangat kuat.

2. Kolom $\mathrm{R}$ Square menunjukan adalah 0,154 adalah pengkuadratan dari koefisien korelasi atau 0,392 x 0,392= 0,154 .

3. R Square disebut juga dengan koefisien determinasi. Hal ini berarti besarnya pengaruh kedisiplinan kerja, prestasi kerja dan semangat kerja terhadap pemberian bonus karyawan adalah sebesar $15 \%$ sedangkan sisanya $(100 \%$ $15 \%=85 \%$ ) dipengaruhi faktor lain.

\section{Uji Simultan}

ANOVA $^{b}$

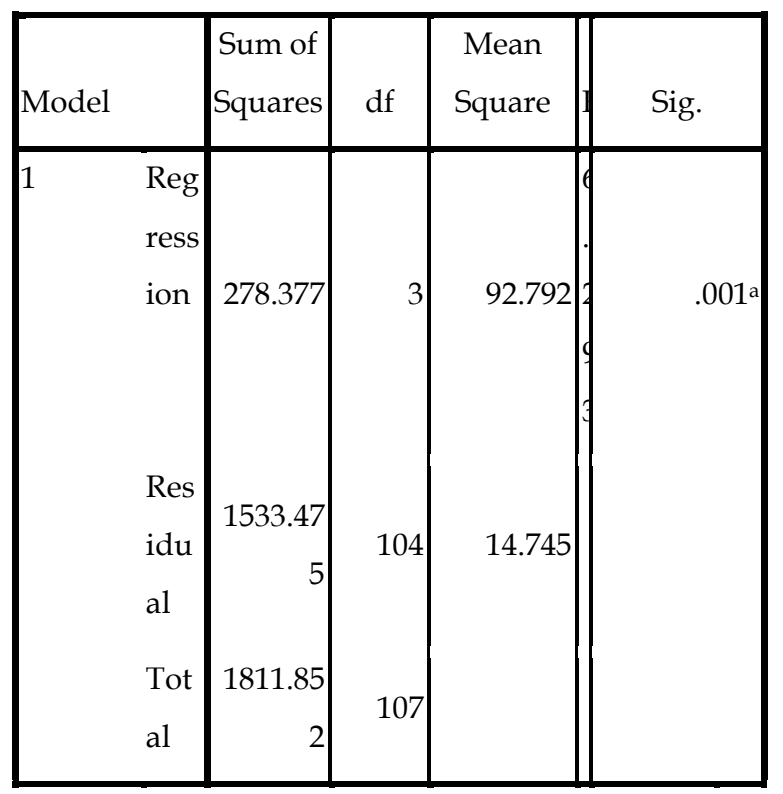

a. Predictors: (Constant), Semangat Kerja, Disiplin Kerja, Prestasi Kerja

b. Dependent c. Variable: Bonus

Sumber: out put SPSS, V.16

Analisis :

Berdasarkan tabel diatas dapat diketahui bahwa uji Anova didapat $F_{\text {hitung }}$ sebesar 6,293 sedang $F_{\text {tabel 2,68 (dari jumlah }}$ variable dikurangi 1) 4 variabel - $1=3$ dan banyaknya sampel 108 didapat $F_{\text {tabel }}$ 2,68 jadi $F_{\text {hitung }}>$ dari $F_{\text {tabel }}$ dengan demikian Ho ditolak dan Ha diterima, artinya terdapat hubungan linear antara variabel 
kedisiplinan kerja, prestasi kerja dan semangat kerja terhadap pemberian bonus karyawan.

\section{KESIMPULAN}

Dari hasil penelitian, analisa dan pembahasan pada hal sebelumnya mengenai analisis pengaruh kedisiplinan kerja, prestasi kerja dan semangat kerja terhadap pemberian bonus karyawan pada PT. Reka Sukses Adipratama maka dapat ditarik kesimpulan sebagai berikut :

Kedisiplinan kerja

a. Berdasarkan hasil jawaban kuesioner yang disebarkan pada PT. Reka Sukses Adipratama pada karyawan bagian staff, bahwa kedisiplinan kerja yang tercipta diperusahaan sudah berjalan dengan baik dan efektif. Ini dapat dilihat dari jawaban responden yang menunjukan bahwa karyawan harus mentaati tata tertib, menjalankan tugas sesuai dengan perintah yang telah ditetapkan dalam perusahaan, sehingga dapat tercipta suatu hubungan yang baik, suasana kerja yang nyaman sehingga dapat meningkatkan prestasi kerja yang dapat membantu tercapainya tujuan yang telah diterapkan.

b. Prestasi kerja
Berdasarkan hasil jawaban kuesioner yang disebarkan pada PT. Reka Sukses Adipratama pada karyawan bagian staff, bahwa prestasi kerja karyawan semakin baik ini terlihat dari jawaban responden yang menunjukan bahwa dengan kedisiplinan kerja, kesiapan kerja, motivasi yang diberikan oleh perusahaan maka dapat meningkatkan prestasi kerjanya serta membantu mencapai tujuan perusahaan.

c. Semangat Kerja

Berdasarkan hasil jawaban kuesioner yang disebarkan pada PT. Reka Sukses Adipratama pada karyawan bagian staff, bahwa semangat kerja karyawan semakin baik ini terlihat dari jawaban responden yang menunjukan bahwa dengan presensi, disiplin, kerja sama, tanggung jawab dan produktivitas dapat meningkatkan semangat kerja dalam melaksanakan pekerjaan yang diberikan oleh atasan dalam bekerja.

d. Pemberian bonus kerja

Berdasarkan hasil jawaban kuisioner yang disebarkan pada PT. Reka Sukses Adipratama pada karyawan bagian staff, bahwa pemberian bonus karyawan yang diterapkan perusahaan sudah dilaksanakan dengan baik ini terlihat dari jawaban kuisioner yang 
menunjukan bahwa dengan Pangabean, Mutiara S. 2004. Manajemen menerapakan kedisiplinan, Sumber Daya Manusia. Ghalia meningkatkan prestasi, semangat kerja, Indonesia.

berpartisipasi dalam kegiatan Robert L. Mathis dan John H. Jackson., perusahaan maka dapat 2006., Human Resource mempengaruhi pemberian bonus yang diterapkan oleh perusahaan.

Management., Jakarta: PT. Salemba Empat

Rucky, Achmad S., 2006., Manajemen Penggajian dan Pengupahan untuk

\section{REFERENSI}

Daft Richard L., 2006., Management., Jakarta: Salemba Empat.

Dessler Gary. 2006., Manajemen Sumber Daya Manusia., Jakarta: PT. Indeks. Hasibuan, Malayu., 2007., Manajemen Sumber Daya Manusia., Jakarta: PT. Bumi Aksara.

Handoko T. Hani., 2008., Manajemen Personalia dan Sumber Daya Manusia., Yogyakarta: BPFEYogyakarta.

J. Leavitt Harold., 2007., Psikologi Manajemen. Edisi Keempat., Jakarta: Erlangga

Mangkunegara, Anwar Prabu., 2005.,

Manajemen Sumber Daya Manusia., Bandung: PT. Remaja Ronda Karya. Mangkunegara, Anwar Prabu., 2006., Evaluasi Kinerja Sumber Daya Manusia. Bandung: PT. Refika Aditama.

Granmedia Pustaka Utama.

Samsudin H. Sadili., 2006., Manajemen Sumber Daya Manusia., Bandung: CV. Pustaka Setia.

Sekaran, Uma., 2006., Metode Penelitian untuk Bisnis. Edisi 4., Jakarta: PT. Salemba Empat.

Siagian, Sondang P., 2006., Manajemen Sumber Daya Manusia., Jakarta: PT. Bumi Aksara.

Simamora, Henry., 2006., Manajemen Sumber Daya Manusia., Yogyakarta: STIP YKPN.

Sirait, Justine T., 2006., Memahami Aspekaspek Pengelolaan Sumber daya Manusia dalam Organisasi., Jakarta: PT. Granmedia Widiasarana Indonesia.

Stephen P. Robbins dan Marry Coulter, 2007,. Manajemen., edisi kedelapan., Jakarta: PT. Indeks. 
Stoner, James A.F., 2006., Manajemen., Jakarta: PT. Indeks.

Supranto, J., 2001., Statistik Teori dan Aplikasi., edisi enam., Jakarta., PT. Erlangga

Bakowatun Wilhelmus W., 2006., Manajemen., Edisi Kelima., Jakarta: Intermedia

www.google.com. 6.11.08. Labels Sistem

Insentif Perusahaan. At 02 : 52. Ayunksyah.

Y. Josephine, "JURNAL TECH-E Implementasi eBudgeting Terhadap Kinerja PT Primer Eka Properti Melalui Pengendalian Internal," Tech-E, vol. 1, no. 1, pp. 1-6, 2017. 